\title{
Intelligent Negotiation Model for Ubiquitous Group Decision Scenarios
}

\author{
João CARNEIRO $\$ 1,2$, Diogo MARTINHO ${ }^{1}$, Goreti MARREIROS ${ }^{1}$, Paulo NOVAIS ${ }^{2}$ \\ $\left({ }^{1}\right.$ GECAD - Knowledge Engineering and Decision Support Group, Institute of Engineering - Polytechnic of Porto, Porto, 4200-072, Portugal) \\ $\left({ }^{2}\right.$ ALGORITMI Centre, at University of Minho, Braga, Portugal) \\ †E-mail: jomrc@isep.ipp.pt
}

Received Oct. 16, 2015; Revision accepted Feb. 20, 2016; Crosschecked Mar 14, 2016

\begin{abstract}
Supporting group decision-making in ubiquitous contexts is a complex task that must deal with a large amount of factors to succeed. Here we propose an approach for an intelligent negotiation model to support the group decision-making process specially designed for ubiquitous contexts. Our approach can be used by researchers that intend to include arguments, complex algorithms and agents' modelling in a negotiation model. It uses a social networking logic due to the type of communication employed by the agents and it intends to support the ubiquitous group decision-making process in a similar way to the real process, which simultaneously preserves the amount and quality of intelligence generated in face-to-face meetings. We propose a new look into this problematic by considering and defining strategies to deal with important points such as the type of attributes in the multicriteria problems, agents' reasoning and intelligent dialogues.
\end{abstract}

Keywords: Group Decision Support Systems, Ubiquitous Computing, Automatic Negotiation, Social Networks, Multi-Agent Systems

doi: 10.1631/FITEE. 1000000

Document code: A

CLC number:

\section{Introduction}

Many existing Group Decision Support Systems $(G D S S)$ prototypes use automatic negotiation models as a strategy to support the decision (Herrera et al., 1997; Maznevski, 1994; Moreno-Jiménez et al., 2008; $\mathrm{Xu}, 2009)$. Argumentation-based negotiation models are one of the most used and best suited automatic negotiation techniques to support the decision-making (Rahwan et al., 2003; Marey et al., 2014). It is consensual that the possibility of justifying a request using an argument facilitates reaching an agreement or solution (Marey et al., 2014; Bonzon et al., 2012). Albeit all the recognized advantages in the use of argumentation models in decision-making, and the

\footnotetext{
\$ Corresponding author: João Carneiro, GECAD - Knowledge Engineering and Decision Support Group, Institute of Engineering Polytechnic of Porto, R. Dr. António Bernardino de Almeida, 431 P4200-072 Porto, Portugal; Tel.: +351 228340 511; Fax: +351 228321 159
}

time necessary to study argumentative models in the area of computer science which can be traced back to a few decades, the truth is that such models have not yet been embraced by organizations. The existing models are barely adaptable to the business world reality, have difficulty in reflecting the decisionmaking natural process, and create a certain discomfort in their use by decision-makers. It is also important to note that the actual evaluation of the argumentation models is not the one an organization would want to use. The fact an argumentation model gives a solution in lesser rounds or in lesser seconds than another, are not the most relevant points for someone who is concerned about using a mechanism to potentiate the decision quality. Maybe because of that, business intelligence techniques have a much higher growth than GDSS.

Looking for studies on argumentation-based negotiation models adapted to group decision support systems, the results are practically inexistent. The few 
existing results are old (Karacapilidis and Papadias, 2001; Marreiros et al., 2010; Karacapilidis and Papadias, 1998) and even if some seemed promising in the way they could be adapted to this area (Kraus et al., 1998; Sierra et al., 1998), the works that came next followed most of the times another path (even with some of them remaining within decision support) Forgetting negotiation models for a moment, we found that even the existing argumentation approaches are not oriented to problems that include multiple agents interacting simultaneously. It is even possible to verify that in the most recent argumentation studies, authors with more than one or two decades of work, point the inclusion of multiple agents as a future expansion for their work (Fan and Toni, 2014; Fan et al., 2014). When agents have "oneto-one" communication the process is simple. However, things become more difficult when an agent receives messages from multiple agents. Another important issue is how most authors test their argumentation models, the majority opt for the "seller-buyer", example (Rahwan et al., 2003; Marey et al., 2014; Karunatillake and Jennings, 2005; Ramchurn et al., 2007; de Melo et al., 2011; El-Sisi and Mousa, 2012), which has a type of dialogue much oriented to that kind of problem.

Defining a type of adaptable dialogue to use in an argumentation-based negotiation model which has the objective to support group decision-making is a complex task. Walton (Walton, 1995) believes that dialogues should be classified based in their primary objective, and presents six major dialogue classes for that: inquisition, persuasion, negotiation, deliberation, demand for information and eristic. However, what is the most adaptable dialogue for a group of people, employees of the same company, whose common objective is not only to solve a certain problem, but at the same time satisfy their own objectives? Maybe a mix of several types of dialogue could be the solution, or creating a new class. This makes it very complex to adapt an argumentation theory to this scenario.

We believe that part of the failure of group decision support systems developed until today is related with the perspective used to analyse the problem and how those systems have been evaluated.

Here we propose an approach for a negotiation model that intends to support the ubiquitous group decision making process similarly to a real process, which simultaneously preserves the amount and quality of intelligence generated in face-to-face meetings and is adapted to be used in a ubiquitous context. Our approach is capable to deal with intelligence because our agents have the possibility to maintain a dialogue about the topic, expressing their opinions and gather information of what they "heard". Our approach is an alternative for researchers that intend to use their specific algorithms, arguments or models to define agents (for instance in terms of behaviours of personality).

The rest of the paper is organized as follows: in the next section is presented our approach, where the theoretical ideas for the negotiation model are described and the model formulation is presented. In the following section, we present the attribute types' definition and in the next section we go through some important ideas such as the agents' reasoning and how our approach fits this context. Finally, some conclusions are taken in the last section, along with the work to be done hereafter.

\section{Proposed Model}

Much of the existing literature that uses agents for negotiation purposes (Huang and Sycara, 2002; Kakas and Moraitis, 2006; Rahwan et al., 2007) mainly considers scenarios where the agents are fully competitive, in which each agent seeks to achieve its own goals (Santos et al., 2010; Rosaci, 2012) or fully collaborative, where all seek to find a solution that satisfies everyone's needs (Yen et al., 2001; Reicher et al., 2005; Allen et al., 2002). In the case of a GDSS that aims to support an organization's decision group to make decisions, this issue should be looked at differently. Considering a system that will have agents, where each agent will represent a decision-maker, a mix of competition and collaboration should then be considered. We could acknowledge that while all the agents are part of the same organization, they should be collaborative in order to achieve the best possible decision for the firm. However, for human nature reasons, that would lose certain existing advantages in the context of meeting. Despite the "all wear the same sweater" philosophy, in a real context the decisionmaker also seeks to achieve his own goals. This happens for several reasons, but in this particular situation we are only interested in highlighting the conviction reasons. The decision-maker considers in 
his logic that his preferred alternative is the best solution to solve the problem and therefore he will defend his alternative until arguments that make him consider a more beneficial alternative are presented. It is this behaviour that enriches the meetings, introduces new knowledge and allows higher quality decisions to be made. This is the behaviour we intend to include in our negotiation model and that we consider to be important to introduce in this kind of systems.

The negotiation model here proposed is inspired by the communication logic used in social networks. The main idea follows two main types of communication: Public Communication $(P C)$ in the form of public posts, and Private Communication
$(\operatorname{PrC})$ in the form of private chat. The visual idea of the communication form is much alike to the one used

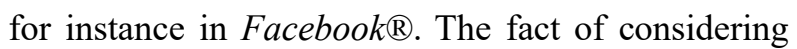
the way of communication used in social networks a good approach to serve as inspiration for this work topic is related to two main factors: the agents communicate in a context similar to the one practiced by the decision-makers in face-to-face meetings and the environment and the agents communication/interaction is easily understood by the participants (decision-makers).

Fig. 1 represents the two different types of communication. The agent is part of a single $P C$ but can have several $\operatorname{PrC}$ simultaneously.

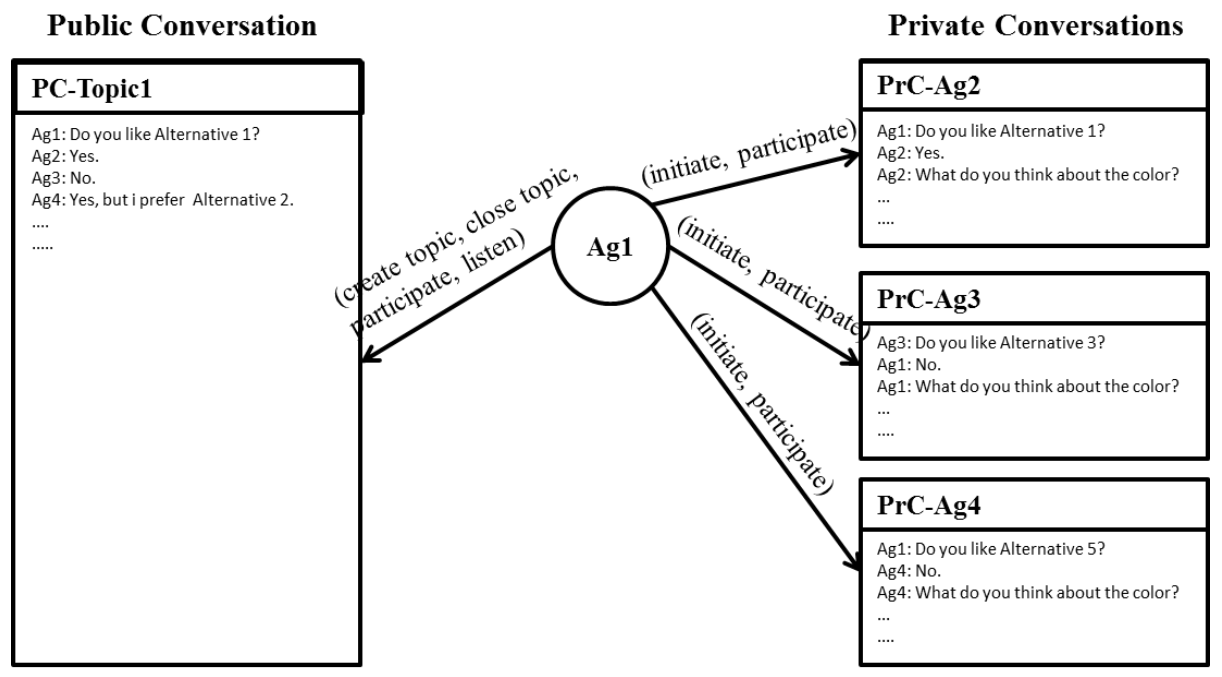

Fig. 1 - The two different types of communication

A $P C$ is an open conversation and its functioning reflects the type of dialogue practiced by the decisionmakers in a real context. Sometimes public conversations or conversations between multiple agents are mentioned, but in practice what happens is that there is a group of agents that exchanges messages where each message has a single receptor. In the case of $P C$, messages are exchanged as how it happens in real life, where a group of people are seating at a table and even when a message has only one recipient it can be heard by all. This allows the agents to gather information and create relationships through the messages they listen, even if those messages are not directed towards them. In $P C$ agents can only address one topic at a time. Any agent can propose the closure of a topic, which will be closed if no other agent has anything else to say. Obviously all agents can participate in a $P C$ and read all the messages.

$\operatorname{PrC}$ are all the private conversations of each participant agent, and as mentioned, an agent can keep several $\operatorname{PrC}$ simultaneously. At most, it can have a $\operatorname{PrC}$ with each one of the other agents. An agent can initiate a $\operatorname{PrC}$ with any other agent provided it does not already exist. A $\operatorname{PrC}$ can stay open during the entire process without being terminated. The existence of $\operatorname{PrC}$ is an advantage over the actual meetings that do not allow simultaneous private conversations during the process.

In literature (to the best of our knowledge) in the 
context of support for group decision-making the agents use requests and questions as a way of communication. The communication allows them to use strategies to persuade the other agents as well as to gather the necessary information to reason about the problem. In addition to questions and requests, in our approach we introduce the concept of statement. The statement is a way of communication that will be used by the agents to demonstrate their points of view. This means agents can share information or perform indirect persuasion through statements. For instance, Agent1 can say "to me consumption is the most important attribute". For example, this action can make Agent2, which considers Agent1 to be the most experienced in the issue that is being discussed, to redefine the importance he gives to the consumption attribute. As mentioned earlier, it is essential to give prominence to the decision process since strategies that propose solutions based on the problem's initial settings end up losing the process's value existent in real meetings. Negotiation automation should continue to allow the existence of two fundamental points: change of opinion/problem reformulation by the decision-makers when they realize/agree with the arguments presented by other interveners, and learning with the assessment of the process by the decision-makers. Statements, requests and questions can be used with and without the inclusion of arguments and can be used in $P C$ and $\operatorname{PrC}$. Counterarguments and acceptance or rejection responses are also made through those three types.

Given this descriptive definition and the underlying motivations of our approach, we now formulate these notions to develop a notationap representation of the schema.

Definition 1: Let $p$ be a multi-criteria problem $(p=$ $(C, A, A g)$ ), where $C$ is the set of considered criteria $\left(C=\left\{c_{1}, c_{2}, \ldots, c_{n}\right\}\right), A$ is the set of considered alternatives $\left(A=\left\{a_{1}, a_{2}, \ldots, a_{m}\right\}\right)$ and $A g$ is the set of all participant agents $\left(A g=\left\{a g_{1}, a g_{2}, \ldots, a g_{k}\right\}\right)$.

Rule 1: Each alternative is related with each criterion. There cannot be an existing alternative with values for criteria that is not considered in the problem.

Example 1.1: Let us consider, as an example, the multi-criteria problem of purchasing a new car. In this problem it will be discussed three criteria and three alternatives. Three agents will participate in the discussion. Therefore $p$ is defined as $p=$ ( $\{\mathrm{c} 1, \mathrm{c} 2, \mathrm{c} 3\},\{\mathrm{a} 1, \mathrm{a} 2, \mathrm{a} 3\},\{\mathrm{ag} 1, \mathrm{ag} 2, \mathrm{ag} 3, \mathrm{ag} 4\})$.

Definition 2: Let $c_{i}$ be a criterion ( $c_{i}=$ $\left\{n_{c_{i}}, v_{c_{i}}, m_{c_{i}}\right\}$ ), where $\forall c_{i} \in C, i \in\{1,2, \ldots, n\}, n_{c_{i}}$ is the name of a particular criterion, $v_{c_{i}}$ is the value of a particular criterion (Numeric, Boolean and Classificatory) and $m_{c_{i}}$ is the greatness associated with the criterion (Maximization, Minimization, Positivity, Negativity and Without Value).

Example 1.2: For the previous example let us consider three criteria: Price, Transmission, Air Conditioning. Each criterion is defined as follows:

$\mathrm{c} 1=\{$ Price, Numeric, Minimization $\} ;$

c2 $=\{$ Transmission, Classificatory, Without Value $\} ;$ c3 $=\{$ Air Conditioning, Boolean, Positivity $\}$.

Definition 3: Let $a_{i}$ be an alternative ( $a_{i}=$ $\left.\left\{n_{a_{i}},\left[c_{1_{a_{i}}}, c_{2 a_{i}}, \ldots, c_{n_{a_{i}}}\right]\right\}\right)$, where $\forall a_{i} \in A, i \in$ $\{1,2, \ldots n\}, n_{a_{i}}$ is the name of a particular alternative and $\left[c_{1 a_{i}}, c_{2_{a_{i}}}, \ldots, c_{n_{a_{i}}}\right]$ is the instantiation of every criteria.

Example 1.3: For the previous example let us consider three alternatives. Each alternative is defined as follows:

a1 $=\{$ Car1, $[10000 €$, Automatic, No $]\} ;$

a2 $=\{$ Car2, [15000€, Manual, Yes $]\}$

$a 3=\{$ Car 3,[12500€, Manual, No $]$.

Definition 4: Let $l_{i}$ be a locution ( $l_{i}=$ $\left\{\right.$ type $_{l_{i}}$, id $_{l_{i}}$, text $_{l_{i}}$, context $\left._{l_{i}}, \operatorname{Var}_{l_{i}}, g_{l_{i}}\right\}$ ), where $i \in$ $\{1,2, \ldots n\}$, type $_{l_{i}}$ is the locution's type (Question, Statement and Request), $i d_{l_{i}}$ is the locution's id, text $_{l_{i}}$ is the text associated to the locution, context $_{l_{i}}$ is the locution's context (Alternative, Criterion or, Without Context), $\operatorname{Var}_{l_{i}}$ is the set of variables associated to the locution (Alternative or Criterion) and $g_{l_{i}}$ is the locution's domain (General or Specific).

The proposed locutions to be considered are specified in Table 1. 
Table 1 Considered Locutions

\begin{tabular}{|c|c|c|c|c|c|c|}
\hline Locution & Type & Id & Text & Context & Variables & Domain \\
\hline Criteria General Preference & Statement & 1 & $\begin{array}{l}\text { "For me the most important } \\
\text { criterion/a is/are } 1,2, \ldots, n "\end{array}$ & Criterion & $\begin{array}{l}\text { Criterion } 1, \\
2, \ldots, \mathrm{n}\end{array}$ & General \\
\hline $\begin{array}{l}\text { Alternatives } \\
\text { Preference }\end{array}$ & Statement & 2 & $\begin{array}{l}\text { "For me the most important } \\
\text { alternative/s is/are } 1,2, \ldots \text {, } \\
n "\end{array}$ & Alternative & $\begin{array}{l}\text { Alternative } 1 \\
2, \ldots, n\end{array}$ & General \\
\hline Criteria General Preference & Question & 3 & $\begin{array}{l}\text { "Which criterion/a you } \\
\text { consider most important?" }\end{array}$ & Criterion & - & General \\
\hline $\begin{array}{ll}\text { Alternatives } & \text { General } \\
\text { Preference } & \end{array}$ & Question & 4 & $\begin{array}{l}\text { "Which alternative/s you } \\
\text { prefer?" }\end{array}$ & Alternative & - & General \\
\hline Criteria Individual Preference & Question & 5 & $\begin{array}{l}\text { "Who considers the } \\
\text { criterion/an as the most } \\
\text { important?" }\end{array}$ & Criterion & $\begin{array}{l}\text { Criterion } \\
1 / 2 / \ldots / n\end{array}$ & Specific \\
\hline $\begin{array}{l}\text { Alternatives } \\
\text { Preference }\end{array}$ & Question & 6 & $\begin{array}{l}\text { "Who prefers the } \\
\text { alternative/s } n ? "\end{array}$ & Alternative & $\begin{array}{l}\text { Alternative } \\
1 / 2 / \ldots / \mathrm{n}\end{array}$ & Specific \\
\hline Agreement & Statement & 7 & "I agree." & $\begin{array}{l}\text { Without } \\
\text { Context }\end{array}$ & - & $\begin{array}{l}\text { Specific/ } \\
\text { General }\end{array}$ \\
\hline Disagreement & Statement & 8 & "I disagree." & $\begin{array}{l}\text { Without } \\
\text { Context }\end{array}$ & - & $\begin{array}{l}\text { Specific/ } \\
\text { General }\end{array}$ \\
\hline No Information & Statement & 9 & $\begin{array}{l}\text { "I do not have that } \\
\text { information." }\end{array}$ & $\begin{array}{l}\text { Without } \\
\text { Context }\end{array}$ & - & $\begin{array}{l}\text { Specific/ } \\
\text { General }\end{array}$ \\
\hline End of Participation & Statement & 10 & $\begin{array}{l}\text { "I have nothing more to } \\
\text { say." }\end{array}$ & $\begin{array}{l}\text { Without } \\
\text { Context }\end{array}$ & - & General \\
\hline Alternative Request & Request & 11 & & & & \\
\hline Accept & Statement & 10 & "I accept." & Alternative & $\begin{array}{l}\text { Alternative } \\
1 / 2 / \ldots / n\end{array}$ & Specific \\
\hline Refuse & Statement & 11 & "I do not accept." & Alternative & $\begin{array}{l}\text { Alternative } \\
1 / 2 / \ldots / n\end{array}$ & Specific \\
\hline
\end{tabular}

Definition 4.1: Let $L$ be the set of all locutions. For a domain $g$ assigned to the locution $l_{i}$ the set of locutions $L_{g}$ is associated if $L_{g} \subset L$ and $\forall l_{i} \in$ $L_{t}, g_{l_{i}}=g$.

Definition 4.2: Let $L$ be the set of all locutions. For a particular type tassigned to the locution $l_{i}$ the set of locutions $L_{t}$ is associated if $L_{t} \subset L$ and $\forall l_{i} \in$ $L_{t}$, type $_{l_{i}}=t$.

Definition 4.3: Let $L$ be the set of all locutions. For a particular criterion $c_{i}$ the set of specific locutions $L_{e_{c_{i}}}$ is associated if $L_{e_{c_{i}}} \subset L, \forall l_{j} \in L_{e_{c_{i}}} g_{l_{j}}=$ specific, $\forall l_{j} \in L_{e_{c_{i}}}, c_{i} \subset \operatorname{Var}_{l_{j}}$ and $\forall l_{j} \notin L_{e_{c_{i}}}, c_{i} \not \subset$ $\operatorname{Var}_{l_{j}}$.

Rule 2: For any locution $l_{j} \in L_{e_{c_{i}}}$, and $c_{i} \subset \operatorname{Var}_{l_{j}}$ there cannot be another locution $l_{k}$ where $c_{i} \subset$ $\operatorname{Var}_{l_{k}}$ and $l_{k} \notin L_{e_{c_{i}}}$.

Definition 4.4: Let $L$ be the set of every locutions. For a particular alternative $a_{i}$ the set of specific locutions
$L_{e_{a_{i}}}$ is associated if $L_{e_{a_{i}}} \subset L, \forall l_{j} \in L_{e_{a_{i}}}, g_{l_{j}}=$ specific, $\forall l_{j} \in L_{e_{a_{i}}} a_{i} \subset \operatorname{Var}_{l_{j}}$ and $\forall l_{j} \notin L_{e_{a_{i}}}, a_{i} \not \subset$ $\operatorname{Var}_{l_{j}}$

Rule 3: For any locution $l_{j} \in L_{e_{c_{i}}}$, and $a_{i} \subset \operatorname{Var}_{l_{j}}$ there cannot be another locution $l_{k}$ where $a_{i} \subset$ $\operatorname{Var}_{l_{k}}$ and $l_{k} \notin L_{e_{a_{i}}}$.

Definition 4.5: Let $L$ be the set of every locutions. For a particular context context the set of general locutions $L_{g e_{\text {context }}}$ is associated if $L_{\text {ge }}$ context $\subset L$, $\forall l_{j} \in L_{g e_{\text {context }}} g_{l_{j}}=$ general $\quad$ and $\quad \forall l_{j} \in$ $L_{g e_{\text {context }}}$, context $t_{l_{j}}=$ context.

Definition 5: Let $m s g_{i}$ be a message ( $m s g_{i}=$ $\left.\left\{l_{m s g_{i}}, A r g_{m s g_{i}}, i d c h_{m s g_{i}}, a g_{e_{m s g_{i}}}, A g_{r_{m s g_{i}}}\right\} \quad\right)$, where $i \in\{1,2, \ldots n\}, l_{m s g_{i}}$ is the locution sent in the message, $A r g_{m s g_{i}}$ is the justification associated to the locution (can be an argument or can be null), $i d c h_{m s g_{i}}$ is the conversation code (the post for $P C$ or the private 
chat for $\operatorname{PrC}$ ), $a g_{e_{m s g_{i}}}$ is the identification of the agent who sent the message and $A g_{r_{m s} g_{i}}$ is the set of the agents who will receive the message (can be 1 or *).

Definition 6: Let $\operatorname{Arg}_{i}$ be an argument $\left(\operatorname{Arg}_{i}=\right.$ $\left\{i d_{\operatorname{Arg}_{i}}\right.$, text $\left._{\operatorname{Arg}_{i}}, \operatorname{Var}_{\operatorname{Arg}_{i}}\right\}$ ), where $i \in\{1,2, \ldots n\}$, $i d_{A r g_{i}}$ is the identification of a particular argument, text $\operatorname{Arg}_{i}$ is the text associated to a particular argument and $\operatorname{Var}_{A r g_{i}}$ is the set of variables associated to a particular argument (can contain alternatives and criteria).

The criteria included in the set of the agent's preferred criteria will also be included in the set of the agent's updated and preferred criteria. Therefore the size of the set of the agent's updated and preferred criteria will always be at least the same or larger than the set of the agent's preferred criteria that is not updated. Likewise, the alternatives included in the set of the agent's preferred alternatives will also be included in the set of the agent's updated and preferred alternatives. This means that the size of the set of the agent's updated and preferred alternatives will always be at least the same or larger than the set of the agent's preferred alternatives that is not updated.

Proposition 1: The system is finite.

Proof 1: One agent $a g_{j}$ that has prefered $n_{c_{a g_{j}}}$ criteria $\in C_{a g_{j}}$ and $n_{a a g_{j}}$ alternatives $\in A_{a g_{j}}$ can initially use $n_{l_{a g_{j}}}$ locutions where

$$
\begin{aligned}
n_{l_{a g_{j}}} & =\sum_{i=0}^{n_{c a g_{j}}} L_{e_{c_{i}}{ }^{\prime}}+\sum_{i=0}^{n_{a_{a g_{j}}}} L_{e_{a_{i}}{ }^{\prime}}+L_{g e_{\text {Criterion }}} \\
& +L_{g e_{\text {Alternative }}}+L_{g e_{\text {Without Context }}}
\end{aligned}
$$

and $n_{l}$ is the sum of all the locutions related to each criteria and alternative preferred by the agent.

Whenever $C_{a g_{j}}$ and $A_{a g_{j}}$ are updated, $n_{c_{\text {new }_{a g}}} \in$

$$
\begin{aligned}
& C_{\text {new }_{a g_{j}}} \text { and } n_{a_{\text {newag }_{j}}} \in A_{\text {new }_{a g_{j}}} . n_{l_{\text {new }_{a g_{j}}}} \text { will be }
\end{aligned}
$$

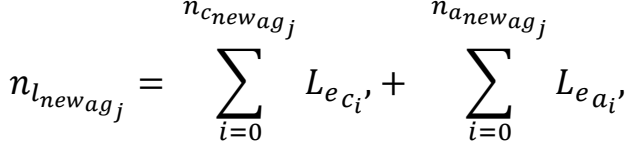

$$
\begin{aligned}
& +L_{g e_{\text {Criterion }}}+L_{g e_{\text {Alternative }}}+L_{\text {ge } e_{\text {Without Context }}}
\end{aligned}
$$

This process is repeated until the agent $a g_{j}$ prefers all

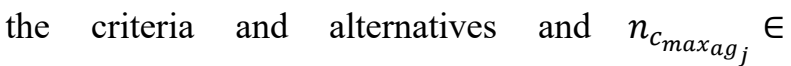

$$
\begin{aligned}
& C_{\max _{a g_{j}}} \text { and } n_{a_{\max } a_{j}} \in A_{\max _{a g_{j}}} . n_{l_{\max _{a g_{j}}}} \text { Will be }
\end{aligned}
$$

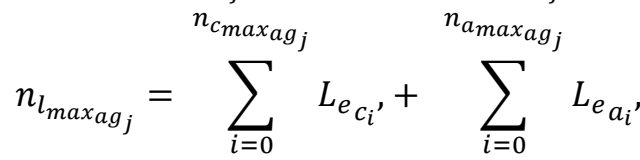

$$
\begin{aligned}
& +L_{g e_{\text {Criterion }}}+L_{g e_{\text {Alternative }}}+L_{g e_{\text {Without Context }}}
\end{aligned}
$$

It is possible to verify that the model is finite as the agent will be able to use, at most, a number of locutions corresponding to the total of criteria and alternatives considered for the multi-criteria problem, and the remaining locutions that do not have a specific context.

The set of locutions defined by each agent will depend in the algorithms used and in each specification of our model. However, each agent will have his particular set of locutions regarding the issues considered by the algorithm. An agent can generate his set of locutions, for instance, based on the: interests configured by the real participant, real participant personality, agent's conflict style, etc.

In order to better understand the process flow of our model, we are going to present some data flow diagrams for each one of the main entities of our model.

\section{Real Participant (Decision-Maker)}

When develop models and applications that will be used in real scenarios, we have to pay special attention to the end users. The end users of our research will be the decision-makers. Considering we are dealing with ubiquitous scenarios, we assume our end users are people with a very busy schedule, that's why we also have been working with techniques to configure multi-criteria problems (Carneiro et al., 2015a). In our proposal, the decision-maker is represented in the "system" by a participant agent. Usually, this agent is seen as someone capable of defending the interests of the decision-maker. In our case, we consider (in order to develop a successful system) this agent as someone who seeks and understands data (and the environment) and other people's perspectives, capable of organizing that data and present more intelligent information to the 
decision-maker so that he can perform better decisions. A successful Ubiquitous Group Decision Support System (UbiGDSS) cannot be one that only presents possible solutions, even when the presented solutions are the best possible. It needs to be capable of presenting information that provides confidence to the decision-maker so that he can reason and make decisions. The decision-maker should be capable of understanding other people's motives. Our model intends to follow the decision-makers during the decision-making process. We believe the best approach would be an iterative process, where the participants can re/configure the problem whenever they want and also understand all the process and other people's perspectives through the interaction with their agents. An interesting fact is that we do not find in the literature any research regarding the kind of information that should be available to support the decision-maker during the process. The lack of these "intelligent reports" is a huge disadvantage when comparing UbiGDSS with business intelligence techniques.

The Fig. 2 represents our perspective on how the real participant's data should flow.

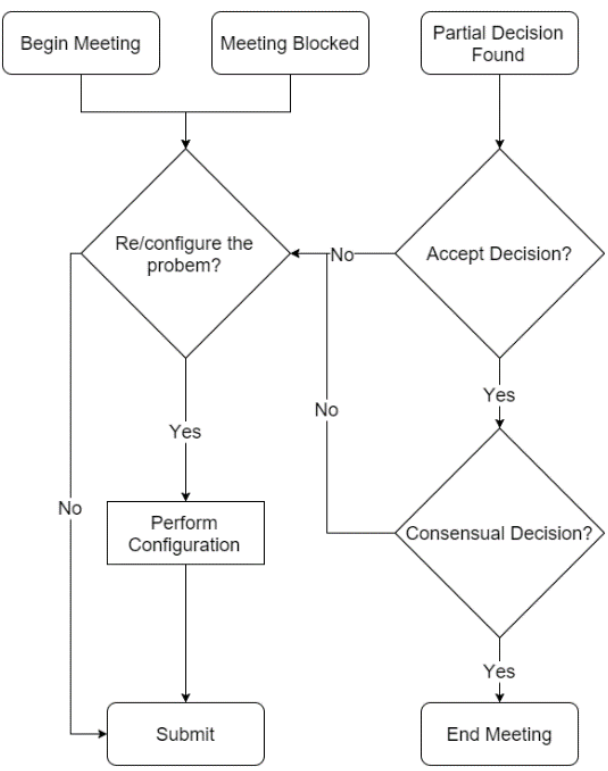

Fig. 2 Real Participant's (Decision-Maker) Flowchart

\section{Facilitator Agent}

In this kind of proposals it is very common to use a facilitator agent. We also consider important to use a facilitator agent; however in our case the facilitator is only responsible to manage the beginning and the end of the meeting. All the dialogue and the messages exchange are in the participant agent side. The Fig. 3 represents our perspective of how the facilitator agent's data should flow.

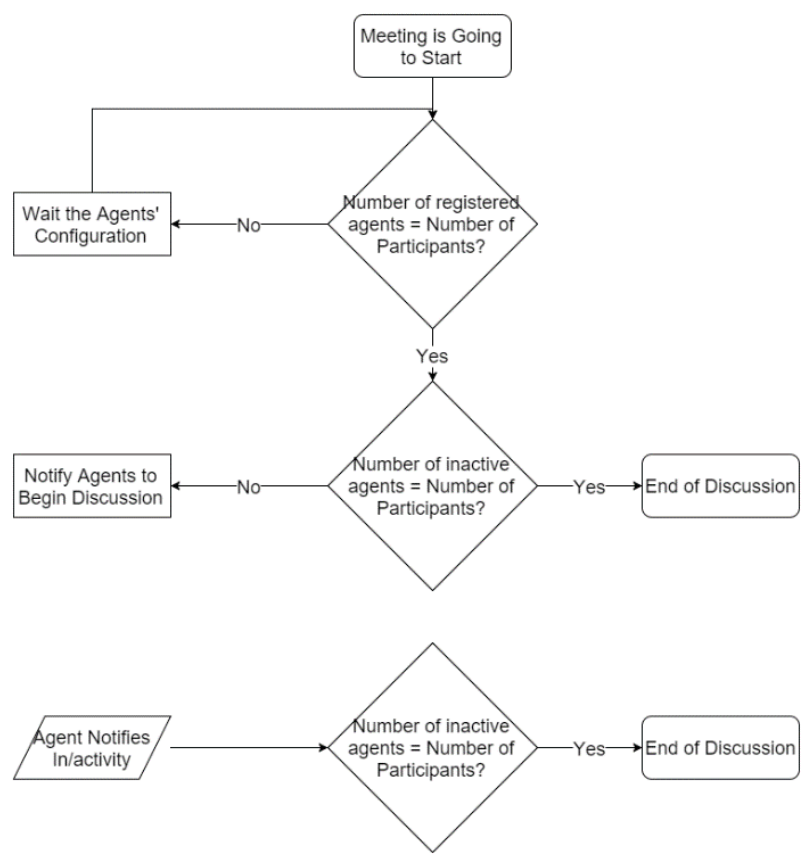

Fig. 3 Facilitator Agent's Flowchart

\section{Participant Agent}

The participant agent plays an essential role in our model. He is the virtual representation of the decision-maker. What it does and when it does will depend on the complexity of the algorithms that are used. What differentiates our model is the capability of those agents to create free dialogues. Usually most of the proposed models are rigid, when defining the order of the events. In our model the agents are free to act according to their intentions. The Fig. 4 represents the participant agent's data flow regarding the public conversations and the Fig. 5 represents the participant agent's data flow regarding the private conversations. The participant agent only reports his inactivity to the facilitator when both "report my inactivity" status in $P C$ and $\operatorname{PrC}$ are verified. 


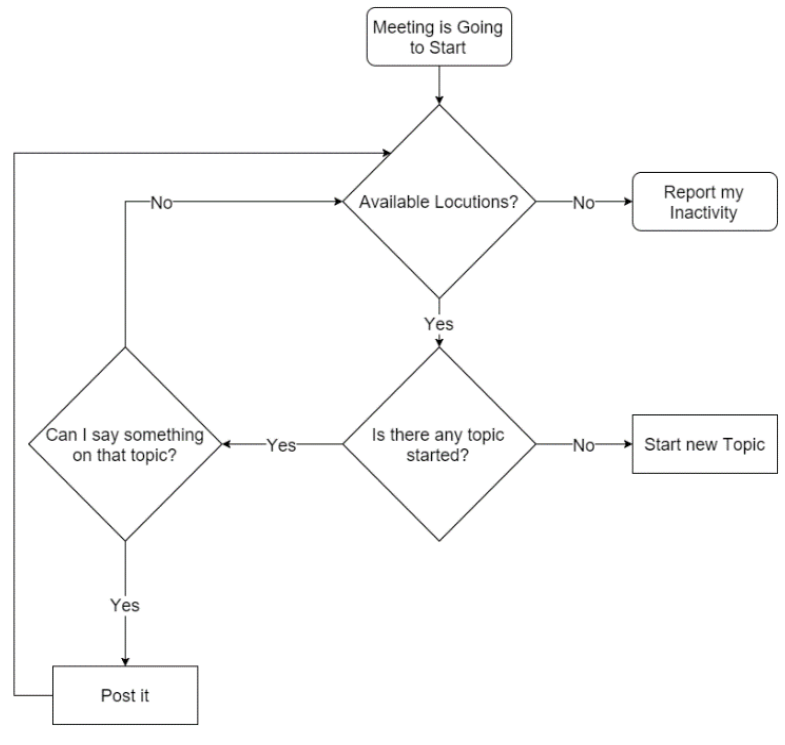

Fig. 4 Participant Agents' Flowchart (Public Conversations)

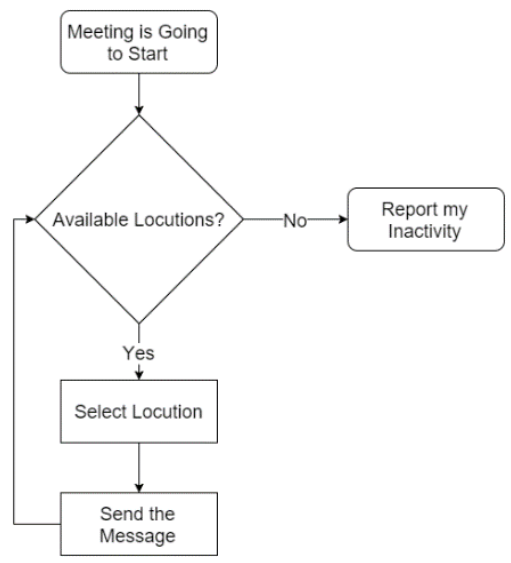

Fig. 5 Participant Agent's Flowchart (Private Conversations)

\section{Attribute Types}

Our model is specifically designed to handle multi-criteria problems. It is not our goal to include any type of natural language mechanism in our prototype. However, we believe it is possible and essential that the agents can understand what is happening in the "conversation". For that, it is necessary to make a proper definition of type of attributes that can be used.

Considering our example of purchasing a new car, one of the attributes was the car's consumption and that attribute was defined as a minimization numerical attribute. If Agent1 says "for me the most important decision factor is consumption" it will allow other agents to argue with Agent1 saying "accept alternative $C$ because it has the lowest consumption". It is possible to understand that this strategy allows the agents to have the ability to perceive a lot of different information. Another major advantage of this approach is the easiness in which an agent will generate perceptible reports for the real participant. Besides being able to present data that supports the decision (for instance, charts, tables, statistics, etc) it is also possible to present the argumentation between the agents and the reason that led the agents to propose a certain decision in a more perceptible way.

The types of attributes considered can be visualized in Fig. 6. Two main types of attributes can be considered:

- Objective: objective attributes are comparable with each other. This means that in the case of the car consumption, if car1 has a lower consumption than car2 and the consumption is a minimization numerical attribute, carl's consumption is invariably better than car2's consumption. The values of the objective attributes are always absolutely true. For instance, if the air conditioning attribute of an alternative is true then the possibility of that car not having air conditioning cannot be considered. There are three types of objective attributes:

- Boolean: are used in situations where the attribute can be classified by only two values, e.g., on/off, yes/no, 0/1, true/false; in this case the most advantageous situation must be specified (true or false). However, this specification is not mandatory. The situation that offers a greater value is considered to be advantageous even if that value does not solve the problem. Considering the same car that with and without air conditioning costs exactly the same price, the fact of having air conditioning is an advantage, even assuming that for health reasons it will not be used;

○ Numerical: the numerical type attributes are used to define measurable attributes, for example: consumption, height, width and distance. This type of attribute is defined as maximization or minimization attribute. However, this specification is not mandatory. For instance, we "always" want to minimize costs, but on the other hand, we always want 
to maximize the profits. However, we may not be interested in minimizing or maximizing an employer's height.

○ Classificatory: this type of attribute is used to specify attributes with a defined and recognized classification. For instance, we can use this type of attribute to specify a car's safety. However, this classification should not be made by someone without credentials. An expert or a classification that has been published in a reference location can be used to make this classification. The classification will function as a scale.
- Subjective: subjective attributes allow agents to perceive what issues do not make sense to argue. For example, it will not make sense to argue that a car is better than another because of the colour. The fact an agent prefers a certain colour (in a certain context) is considered by this type of attribute as a personal taste which cannot be argued. Other examples of subjective attributes (always depends on the context) are: car design, food taste, beauty, sound quality, etc.

\section{Attributes}

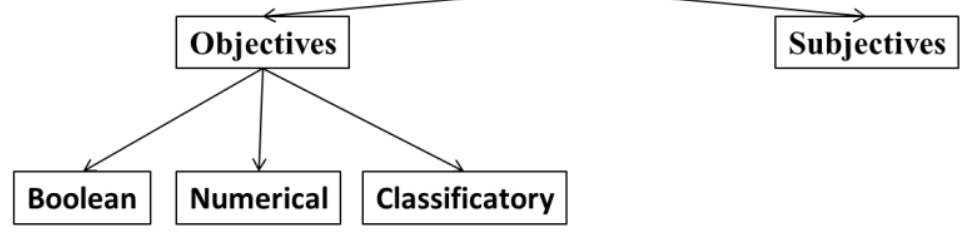

Fig. 6 Attributes' Types

We believe this proposal on the types of attributes for the multi-criteria problem is simple but effective. This way it is possible to set a wide number of problems with a strategy that allows agents to understand about what they are arguing. We believe this approach makes the agents as well as the dialogues more intelligent allowing richer and more perceptible outputs.

\section{Discussion}

To Jennings and Wooldridge an intelligent agent is capable of flexible autonomous actions in order to meet its design objectives (Wooldridge and Jennings, 1995). To them, an intelligent agent needs to be: responsive, proactive and social (for further information about these definitions see (Wooldridge and Jennings, 1995)). To Wooldridge what makes a rational agent is its autonomy (Wooldridge, 2000). In the last decades we have seen many examples in literature that address the topic of intelligent agents (Müller, 1996; Sycara et al., 1996; Jennings and Wooldridge, 1998). It is also known that there are agents that perform the same task with more intelligence than others. However, it is known that in the case of humans, the reactive decision is processed by the brain in a different location of the proactive decision. In the case of agents or computational systems the proactive decision can exist but always in a simulated way.

On the subject of intelligent and rational agents, there is a relevant point that deserves attention regarding group decision-making support systems. Let's suppose we have a system that can rapidly propose a solution to a certain problem according to the decision-makers preferences. It is obvious that this indicator is not enough to know whether the system is good or bad. The proposed solutions can always be unacceptable for the decision-makers, making the system useless. However, let us consider the system can always propose acceptable solutions for the decision-makers, ending up having a great impact on a particular organization. Taking into account these details it would be hypothetically possible to say this system had quality. However, this may not be true. When someone wants to develop a negotiation model to adapt to a group decision-making support system there is an important factor to take into account and that is often forgotten. In the case of face-to-face meetings the decision-makers have time to think over the subject during the process, and usually they start the meeting with certain beliefs which are then changed after hearing others' opinion and argumentations. Sometimes our opinion changes 
when new knowledge is shared with us or when the arguments used invalidate our logic. This fact is what makes face-to-face meetings the preferred choice to make important decisions, and no system is still prepared to deal with such situation. The way models and systems are designed make this crucial part of a real meeting to be lost. We think that research on negotiation models for group decision-making support systems needs to start concerning about such fact. It is important for the agent to have the capability to seek to understand why other agents have other preferences, and not only seek information that allows him to achieve his goals while forgetting that on the other side there may be an agent that can change of opinion even if he did not share his initial convictions with the group.

In the approach here presented, and as already explained, it is intended that the agents communicate in public and private conversations. Public communication is visible by all agents even if it is not directed towards a specific agent. As such, an agent will be listening to a public conversation even if he is not part of it. The agent shall gather information on the messages exchanged publically and then process that information. The idea here is that the agent studies the relationships that are being created as the information is exchanged. In a real meeting, if one of the decision-makers shows his preference for a certain alternative or an attribute that is also my favourite, in that instant a connection between us is created because we share that in common.

Another topic that also will be part of the agents' reasoning and whose advantages have already been previously addressed is the capability to seek to understand the reason behind other agents' preferences. If we think clearly, this agents' reasoning is very similar to what happens in reality: a decisionmaker seeks to understand other decision-makers' opinion. Again, this will allow to generate a richer argumentation as well as to generate more useful and elaborated reports to be analysed by the decisionmaker. The agent will have the ability to understand other agents' opinions by analysing and questioning them on the evaluation and importance given to the attributes. In the example of buying a car, if an agent gives much importance to the consumption and that agent has a preferred car which is the one with the lowest consumption, another agent can deduce that this is why he chooses that alternative. This will allow him to tell the agent to switch to his preference of another car which has a slightly higher consumption but is much cheaper, arguing that the difference he will spend on fuel is insignificant.

Finally, the agents should have the ability to analyse the prediction they make on their satisfaction, that is, the prediction on their perception of the decision quality at a given moment, taking into account the outcome they are predicting to happen. For that, they will use our model on satisfaction analysis previously published by us (for further information read (Carneiro et al., 2014a; Carneiro et al., 2014b). The fact they have the ability to analyse the final satisfaction of the decision-maker they represent makes them more intelligent. This allows them to know when they have to stop defending their favourite alternative and bet on another also that is also preferred (although less) that will give them a greater final satisfaction had another alternative been chosen. The model should also predict the group final satisfaction when their goal is a decision that brings high satisfaction for all the elements. Satisfaction analysis will also be useful for blocked situations and will help the agents to better understand whether or not to accept requests from other agents.

Our work brings a new refreshing perspective in the context of GDSS. The type of communication performed by agents has never been suggested before in the literature (to the best of our knowledge). We believe that our work has similarities with the one proposed by (Marreiros et al., 2010), but our approach has the great advantage to offer an easy understanding of the dialogues conducted by agents. Besides this, most of the works about GDSS that were proposed in literature in the last decade use fuzzy logic as a mechanism to achieve a solution (Kar, 2014; Bashiri and Hosseininezhad, 2009; Zhang et al., 2009). This makes it impossible to justify preferences and becomes a very non-interactive process performed by decision-makers. Our approach takes advantage of the benefits inherent to the use of argumentation, such as: be possible to justify requests and statements, allow introducing new knowledge (Rahwan et al., 2003; ElSisi and Mousa, 2012). It is also important to mention that in ubiquitous contexts most proposed systems will not take advantage of the benefits inherent to group decision-making (Dennis, 1996; Huber, 1984). 
This issue affects decision-makers that cannot gather at the same place and time and that can only interact with each other by using the GDSS. The result will be an increase of frustration of decision-makers, which will lead to most of them giving up on using the system (Paul et al., 2004). Another important point of our approach is that it takes advantage of group decision-making, by creating a process (Dean and Sharfman, 1996). Some works make use of mechanisms that search immediately for a solution preventing any further reasoning of decision-makers (Gorsevski et al., 2013). Our approach allows decision-makers to keep changing their preferences and understand what is happening throughout the process. This leads to a reflected and justified change of opinion. In addition, many existing works in literature do not follow the advantages of group decision-making simply because they cannot promote interaction between decision-makers (Alonso et al., 2010; Tavana et al., 1993). The approach here presented has been defined in a way that allows agents to understand the entire decision-making process and be able to express their opinion through a problem reconfiguration. Besides this, the type of communication is much more explicit due to the proposed attributes' definition. Alonso et al. (2010) have presented a very interesting work using Delphi's method (which is common for this type of context, see (Guo et al., 2005; Postma et al., 2013; Burke and Chidambaram, 2003)). The great advantage of our work compared to this approach is that it motivates the interaction and the interest to understand why other decision-makers have different opinions. In their approach, there is no such thing as interaction between "experts". This problem is also common to all of other works that used the Delphi's method in the GDSS context.

\section{Conclusion and Future Work}

The group decision support systems have been studied in the last three decades. However, after all this time, they are still not being accepted by the industry. Regardless the amount of artificial intelligence techniques applied, they still have too many limitations, especially in situations with time/space constraints. Furthermore, there are big challenges regarding the processes used to evaluate and validate these systems. The processes' evaluation used allows saving good scientific results in certain cases but do not transmit enough confidence so that the industry can understand all the potential of these systems.

In order to support the group decision-making in situations with time/space constraints, the GDSS evolved for the so-called Ubiquitous GDSS (UbiGDSS). They are the ultimate cleavage of GDSS. With the appearance of UbiGDSS some other problems appeared, for instance, how to: overcome the lack of human-interaction, understand the decision quality perception in the perspective of each decisionmaker and overcome the communication issues.

One of the usual techniques in UbiGDSS is automated negotiation. The idea behind automated negotiation, as for instance argumentation, is allowing agents to find a solution through an intelligent dialogue. However, there are no specific defined dialogues for these situations, plus there are only a few argumentation-based negotiation models proposed in literature where the majority was defined before the appearance of UbiGDSS. Going deeply, we can also verify that even the argumentation theories have difficulty in adapting to this scenario.

Here we propose a theoretical negotiation model specifically planned for UbiGDSS. More particularly, we propose new approaches on topics such as the type of attributes and dialogues. In addition to these specific proposals, this topic is addressed under a new look and approach. Multiple reflections are shared, and the most important issues are analysed that in the opinion of authors have been the cause of the GDSS problems.

The model proposed in this paper uses a social networking logic due to the type of communication employed by the agents. Our approach intends to support the ubiquitous group decision-making process, in a similar way to a real process, while simultaneously preserving the quantity and quality of intelligence generated in face-to-face meetings and is adapted to be used in a ubiquitous context. Agents are capable of performing dialogues about the problem, understand the messages of others agents and are capable of using arguments in any kind of used locutions. The kind of knowledge created by agents in our model can be used to bring UbiGDSS to a higher level. 
As for future work there are still a lot of things that need to be done. We will work on the creation of an argumentation framework to be included in our model. At a later stage we will develop a new prototype that will include all the topics addressed here and others previously published. We believe that in the end we can draw strong conclusions on the results obtained from using this new look over automatic negotiation in group decision-making support systems.

As a final remark, we can say that there is a lot of work to do to adapt GDSS to this new Era. This is a very complex area and involves so many other different areas, but working in this field is very exciting and can result in outstanding results.

\section{Acknowledgements}

This paper is a revised and an expanded version of a paper entitle "An Approach for a Negotiation Model Inspired on Social Networks" presented at International Conference on Practical Applications of Agents and Multi-Agent Systems 2015, Salamanca, Spain (Carneiro et al., 2015b). This work has been supported by COMPETE Programme (operational programme for competitiveness) within project POCI-01-0145-FEDER-007043, by National Funds through the FCT - Fundação para a Ciência e a Tecnologia (Portuguese Foundation for Science and Technology) within the Projects UID/CEC/00319/2013, UID/EEA/00760/2013, and the João Carneiro $\mathrm{PhD}$ grant with the reference SFRH/BD/89697/2012 and by Project MANTIS Cyber Physical System Based Proactive Collaborative Maintenance (ECSEL JU Grant nr. 662189).

\section{References}

Herrera, F., Herrera-Viedma, E. , Verdegay, J., 1997. A rational consensus model in group decision making using linguistic assessments. Fuzzy Sets and Systems, 88, 31-49.

Maznevski, M. L., 1994. Understanding our differences: Performance in decision-making groups with diverse members. Human relations, 47, 531-552.

Moreno-Jiménez, J., Aguarón, J. , Escobar, M., 2008. The core of consistency in AHP-group decision making. Group Decision and Negotiation, 17, 249-265.

$\mathrm{Xu}, \mathrm{Z} ., 2009$. An automatic approach to reaching consensus in multiple attribute group decision making. Computers \& Industrial Engineering, 56, 1369-1374.
Rahwan, I., Ramchurn, S. D., Jennings, N. R., Mcburney, P., Parsons, S. , Sonenberg, L., 2003. Argumentation-based negotiation. The Knowledge Engineering Review, 18, 343-375.

Marey, O., Bentahar, J., Asl, E. K., Mbarki, M. , Dssouli, R., 2014. Agents' Uncertainty in Argumentation-based Negotiation: Classification and Implementation. Procedia Computer Science, 32, 61-68.

Bonzon, E., Dimopoulos, Y., Moraitis, P. Knowing each other in argumentation-based negotiation. Proceedings of the 11th International Conference on Autonomous Agents and Multiagent Systems-Volume 3, 2012. International Foundation for Autonomous Agents and Multiagent Systems, 1413-1414.

Karacapilidis, N. , Papadias, D., 2001. Computer supported argumentation and collaborative decision making: the HERMES system. Information systems, 26, 259-277.

Marreiros, G., Santos, R., Ramos, C. , Neves, J., 2010. Context aware emotional model for group decision making.

Karacapilidis, N. , Papadias, D., 1998. A group decision and negotiation support system for argumentation based reasoning. Learning and Reasoning with Complex Representations. Springer.

Kraus, S., Sycara, K. , Evenchik, A., 1998. Reaching agreements through argumentation: a logical model and implementation. Artificial Intelligence, 104, 1-69.

Sierra, C., Jennings, N. R., Noriega, P. , Parsons, S., 1998. A framework for argumentation-based negotiation. Intelligent Agents IV Agent Theories, Architectures, and Languages. Springer.

Fan, X. , Toni, F., 2014. Decision making with assumptionbased argumentation. Theory and Applications of Formal Argumentation. Springer.

Fan, X., Toni, F., Mocanu, A., Williams, M. Dialogical twoagent decision making with assumption-based argumentation. Proceedings of the 2014 international conference on Autonomous agents and multi-agent systems, 2014. International Foundation for Autonomous Agents and Multiagent Systems, 533-540.

Karunatillake, N. C. , Jennings, N. R., 2005. Is it worth arguing? Argumentation in Multi-Agent Systems. Springer.

Ramchurn, S. D., Sierra, C., Godo, L., Jennings, N. R., 2007. Negotiating using rewards. Artificial Intelligence, 171, 805-837.

De Melo, C. M., Carnevale, P., Gratch, J. The effect of expression of anger and happiness in computer agents on negotiations with humans. The 10th International Conference on Autonomous Agents and Multiagent Systems-Volume 3, 2011. International Foundation for Autonomous Agents and Multiagent Systems, 937-944.

El-Sisi, A. B. , Mousa, H. M. Argumentation based negotiation in multiagent system. Computer Engineering \& Systems (ICCES), 2012 Seventh International Conference on, 2012. IEEE, 261-266. 
Walton, D., 1995. Commitment in dialogue: Basic concepts of interpersonal reasoning, SUNY press.

Huang, P. , Sycara, K. A computational model for online agent negotiation. System Sciences, 2002. HICSS. Proceedings of the 35th Annual Hawaii International Conference on, 2002. IEEE, 438-444.

Kakas, A. , Moraitis, P. Adaptive agent negotiation via argumentation. Proceedings of the fifth international joint conference on Autonomous agents and multiagent systems, 2006. ACM, 384-391.

Rahwan, I., Sonenberg, L., Jennings, N. R. , Mcburney, P., 2007. Stratum: A methodology for designing heuristic agent negotiation strategies. Applied Artificial Intelligence, 21, 489-527.

Santos, R., Marreiros, G., Ramos, C., Neves, J. , Bulas-Cruz, J., 2010. Using personality types to support argumentation. Argumentation in Multi-Agent Systems. Springer.

Rosaci, D., 2012. Trust measures for competitive agents. Knowledge-Based Systems, 28, 38-46.

Yen, J., Yin, J., Ioerger, T. R., Miller, M. S., Xu, D. , Volz, R. A. Cast: Collaborative agents for simulating teamwork. International Joint Conference on Artificial Intelligence, 2001. LAWRENCE ERLBAUM ASSOCIATES LTD, 1135-1144.

Reicher, S., Haslam, S. A. , Hopkins, N., 2005. Social identity and the dynamics of leadership: Leaders and followers as collaborative agents in the transformation of social reality. The Leadership Quarterly, 16, 547-568.

Allen, J., Blaylock, N. , Ferguson, G. A problem solving model for collaborative agents. Proceedings of the first international joint conference on Autonomous agents and multiagent systems: part 2, 2002. ACM, 774-781.

Carneiro, J., Martinho, D., Marreiros, G. , Novais, P., 2015a. Individual Definition of Multi-Criteria Problems in Ubiquitous GDSS.

Wooldridge, M. , Jennings, N. R., 1995. Intelligent agents: Theory and practice. The knowledge engineering review, $10,115-152$.

Wooldridge, M. J., 2000. Reasoning about rational agents, MIT press.

Müller, J. P., 1996. The design of intelligent agents: a layered approach, Springer.

Sycara, K., Pannu, A., Williamson, M., Zeng, D. , Decker, K., 1996. Distributed intelligent agents. IEEE Intelligent Systems, 11, 36-46.

Jennings, N. R. , Wooldridge, M., 1998. Applications of intelligent agents. Agent technology. Springer.

Carneiro, J., Santos, R., Marreiros, G. , Novais, P., 2014a. Overcoming the Lack of Human-Interaction in Ubiquitous Group Decision Support Systems.

Carneiro, J., Santos, R., Marreiros, G. , Novais, P., 2014b. Understanding Decision Quality through Satisfaction. Highlights of Practical Applications of Heterogeneous Multi-Agent Systems. The PAAMS Collection. Springer.
Kar, A. K., 2014. Revisiting the supplier selection problem: An integrated approach for group decision support. Expert systems with applications, 41, 2762-2771.

Bashiri, M. , Hosseininezhad, S. J., 2009. A fuzzy group decision support system for multifacility location problems. The International Journal of Advanced Manufacturing Technology, 42, 533-543.

Zhang, G., Ma, J. , Lu, J., 2009. Emergency management evaluation by a fuzzy multi-criteria group decision support system. Stochastic Environmental Research and Risk Assessment, 23, 517-527.

Dennis, A. R., 1996. Information exchange and use in small group decision making. Small Group Research, 27, 532550.

Huber, G. P., 1984. Issues in the design of group decision support sytems. MIS quarterly, 195-204.

Paul, S., Seetharaman, P. , Ramamurthy, K. User satisfaction with system, decision process, and outcome in GDSS based meeting: an experimental investigation. Proceedings of the Proceedings of the 37th Annual Hawaii International Conference on System Sciences (HICSS'04)-Track 1-Volume 1, 2004. IEEE Computer Society, 10037.2.

Dean, J. W. , Sharfman, M. P., 1996. Does decision process matter? A study of strategic decision-making effectiveness. Academy of management journal, 39, 368392.

Gorsevski, P. V., Cathcart, S. C., Mirzaei, G., Jamali, M. M., Ye, X. , Gomezdelcampo, E., 2013. A group-based spatial decision support system for wind farm site selection in Northwest Ohio. Energy Policy, 55, 374-385.

Alonso, S., Herrera-Viedma, E., Chiclana, F. , Herrera, F., 2010. A web based consensus support system for group decision making problems and incomplete preferences. Information Sciences, 180, 4477-4495.

Tavana, M., Kennedy, D. T., Rappaport, J., Ugras, Y. J., 1993. An AHP-Delphi group decision support system applied to conflict resolution in hiring decisions. Journal of Management Systems, 5, 49-74.

Guo, C., Guo, K., Lin, W. , Lin, Z. The research on the software architecture of negotiatory synthetical forecasting GDSS based on J2EE. Computer Supported Cooperative Work in Design, 2005. Proceedings of the Ninth International Conference on, 2005. IEEE, 27-32.

Postma, T. J., Takkenberg, C. T. , Terpstra, S. A GDSS methodology for personnel planning in rheumatology. Decision Support in Public Administration: Proceedings of the IFIP TC8/WG8. 3 Working Conference on Decision Support in Public Administration, Noordwijkerhout, The Netherlands, 13-14 May, 1993, 2013. Elsevier, 149.

Burke, K. , Chidambaram, L. Mini-track: Distributed Group Support Systems (DGSS). null, 2003. IEEE, 16.

Carneiro, J., Marreiros, G. , Novais, P. 2015. An Approach for a Negotiation Model Inspired on Social Networks. PAAMS, 2015b. 